\title{
Tratamento químico de sementes de trigo ${ }^{1}$
}

\author{
Diego de Castro Hossen², Edison dos Santos Corrêa Júnior ${ }^{2}$, \\ Sérgio Guimarães ${ }^{2}$, Ubirajara Russi Nunes ${ }^{3}$, Leandro Galon ${ }^{4}$
}

\begin{abstract}
Chemical treatment of wheat seeds

Treating wheat seeds with insecticides and fungicides is important for protecting them against insects and diseases. This study aimed to evaluate the effects of chemical treatments on the physiologic quality of wheat seeds. The experiment was installed in a completely randomized design, with four replications, in a $2 \times 4$ factorial scheme, being the A factor composed by wheat cultivars (Quartzo and Pampeano) and the B factor by insecticides and fungicides: control and, for each $100 \mathrm{~kg}$ of seeds, $21 \mathrm{~g}$ of the active ingredient (a.i.) of thiametoxan, $55 \mathrm{~g}$ a.i. of carboxin + thiram and $21+55 \mathrm{~g}$ a.i. of thiametoxan + carboxin + thiram. The thiametoxan ( $21 \mathrm{~g}$ a.i. $)$ promoted a higher performance, concerning germination, germination speed index and fresh and dry matter weight, for the Quartzo cultivar. A higher dry matter accumulation was observed for the Pampeano cultivar, under the application of carboxin + thiram, at the $55 \mathrm{~g}$ a.i. dose. Both cultivars performed better, concerning the accelerated aging test, under the application of thiametoxan + carboxin + thiram $(21+55 \mathrm{~g}$ a.i. $)$. The seed treatments resulted in healthier seedlings, which will lead to more uniform plants stands, according to the higher germination percentage or protection against pests.
\end{abstract}

KEY-WORDS: Triticum aestivum L.; winter cereals; grain yield; insecticide; fungicide.

O tratamento de sementes de trigo é essencial, sendo uma das medidas capazes de reduzir o inóculo vinculado à semente. Em muitos casos, apesar de não apresentar sintomatologia externa, as sementes podem estar infectadas por patógenos causadores de doenças, que podem aparecer no desenvolvimento da cultura, em estágios mais avançados (Dhingra 2005).

Ohlson et al. (2010) ressaltam que o trigo semeado na região meridional do Brasil tem apre-

\section{RESUMO}

O tratamento de sementes de trigo com inseticidas e fungicidas é importante para proteger as mesmas da incidência de insetos e doenças. Objetivou-se, com este trabalho, avaliar os efeitos de tratamentos químicos sobre a qualidade fisiológica de sementes de trigo. O experimento foi instalado em delineamento inteiramente casualizado, com quatro repetições, em esquema fatorial $2 \times 4$, sendo o fator A composto por cultivares de trigo (Quartzo e Pampeano) e o B por inseticidas e fungicidas: testemunha e, para cada $100 \mathrm{~kg}$ de sementes, aplicou-se $21 \mathrm{~g}$ do ingrediente ativo (i.a.) de tiametoxam; $55 \mathrm{~g}$ i.a. de carboxina + thiram e $21+55$ g i.a. de tiametoxam + carboxina + thiram. O tiametoxam (21 g i.a.) resultou em melhor desempenho, quanto à germinação, índice de velocidade de germinação e peso de massa fresca e seca, para a variedade Quartzo. Ocorreu maior acúmulo de massa seca para a variedade Pampeano, ao se aplicar carboxina + thiram, na dose de 55 g i.a. As duas cultivares apresentaram melhor desempenho, no teste de envelhecimento acelerado, na presença de tiametoxam + carboxina + thiram $(21+$ 55 g i.a.). O tratamento de sementes proporcionou plântulas mais vigorosas, o que resultará em estandes de plantas mais uniformes, em função da maior percentagem de germinação ou da proteção contra pragas.

PALAVRAS-CHAVE: Triticum aestivum L.; cereais de inverno; inseticida; fungicida.

sentado sérios problemas de qualidade da semente, especialmente em razão da ocorrência de chuvas, no período de pré-colheita, e de danos mecânicos causados na colheita, secagem e armazenamento, uma vez que é armazenado durante o verão, recebendo interferência de fatores como temperatura, umidade relativa do ar e pragas de armazenamento.

Assim, sementes de trigo necessitam da utilização de produtos que forneçam maior prote-

1. Trabalho recebido em mar./2013 e aceito para publicação em mar./2014 ( $n^{\circ}$ registro: PAT 23117).

2. Universidade Federal do Pampa (Unipampa), Faculdade de Agronomia, Itaqui, RS, Brasil.

E-mails: diegohossen@hotmail.com, cuchaitaqui@gmail.com, sergioguimaraessg@hotmail.com.

3. Universidade Federal de Santa Maria (UFSM), Centro de Ciências Rurais, Departamento de Fitotecnia, Santa Maria, RS, Brasil.E-mail: russinunes@yahoo.com.br.

4. Universidade Federal da Fronteira Sul (UFFS), Erechim, RS, Brasil.E-mail: leandro.galon@uffs.edu.br. 
ção contra doenças, ataque de insetos e condições climáticas adversas, no momento da semeadura (Steiner et al. 1989).

Ressalta-se que a proteção fitossanitária das sementes de trigo apresenta relevante importância contra a ação de pragas. Ao mesmo tempo, o uso de sementes de alta qualidade, tanto fisiológica quanto sanitária, pode favorecer a obtenção de estande adequado e plântulas vigorosas, o que poderá incrementar o rendimento de grãos das lavouras de trigo (Lima et al. 2006), especialmente na fronteira oeste do Rio Grande do Sul, onde são escassos os estudos relacionados à sanidade das sementes.

Desse modo, objetivou-se avaliar os efeitos de diferentes tratamentos químicos sobre a qualidade fisiológica de sementes de trigo.

O trabalho foi realizado no Laboratório de Sementes da Universidade Federal do Pampa, Campus Itaqui (RS), no ano agrícola 2011/2012. O delineamento experimental adotado foi inteiramente casualizado, em esquema fatorial $2 \times 4$, com quatro repetições. Para o fator A, alocou-se as cultivares de trigo (Pampeano e Quartzo) e, para o B, os produtos (inseticida e fungicidas indicados na dose de ingrediente ativo e/ou na dose de produto comercial, respectivamente) usados para tratar $100 \mathrm{~kg}$ de sementes: tiametoxam $(21 \mathrm{~g}$ ou $60 \mathrm{~mL})$; carboxina + thiram $(55 \mathrm{~g}$ ou $275 \mathrm{~mL})$; tiametoxam + carboxina + thiram $(21+55 \mathrm{~g}$ ou $60+275 \mathrm{~mL})$ e uma testemunha sem produto.

Após a aplicação dos produtos, as sementes foram acondicionadas em sacos plásticos, para homogeneização dos mesmos. Em seguida, foram postas para secagem à sombra e embaladas em sacos de papel, até o início dos testes.

As seguintes variáveis foram analisadas:

a) Peso de mil sementes (sementes não tratadas): foram utilizadas amostras formadas ao acaso, com quatro repetições de 1.000 sementes, as quais, em seguida, foram pesadas. $O$ resultado obtido foi a média das quatro determinações, expressa em gramas (Brasil 2009);

b) Germinação: realizada com quatro repetições de 50 sementes, para cada tratamento, utilizando-se rolos de papel Germitest umedecidos com água até 2,5 vezes o seu peso seco, mantidos a $20^{\circ} \mathrm{C}$, em câmaras próprias para germinação. A contagem final foi realizada aos sete dias após a semeadura (Brasil 2009), computando-se a percentagem de plântulas normais; c) Índice de velocidade de germinação (IVG): aferido em conjunto com o teste de germinação, de acordo com metodologia proposta por Maguire (1962);

d) Teste de frio: determinado com quatro repetições de 50 sementes, para cada tratamento, acondicionadas em rolos umedecidos, mantidos no interior de sacos plásticos, e, depois, transferidas para câmara fria, a $10^{\circ} \mathrm{C}$, por sete dias. Posteriormente, $\mathrm{o}$ material foi transferido para germinador, a $20^{\circ} \mathrm{C}$, com avaliação aos cinco dias, considerando-se vigorosas as sementes que possibilitaram o desenvolvimento de plântulas sem quaisquer alterações (Fanan et al. 2006);

e) Envelhecimento acelerado: realizado em minicâmaras, conforme metodologias propostas por Marcos Filho (1999) e Modarresi et al. (2002);

f) Comprimento de plântulas: determinado ao final do teste de germinação, nas plântulas normais, aos 10 dias após a implantação do teste, com régua graduada em centímetros (Nakagawa 1999);

g) Massa fresca e seca de plântulas: determinadas juntamente com o teste de comprimento de plântulas, de acordo com Nakagawa (1999).

Os dados foram submetidos à análise de variância, pelo teste $\mathrm{F}$, e, quando significativas, as médias dos tratamentos foram comparadas pelo teste Tukey, a 5\%. Não houve interação entre os fatores testados (tratamentos de sementes $\mathrm{x}$ variedades de trigo), para todas as variáveis avaliadas.

O peso de 1.000 sementes de trigo das cultivares Quartzo e Pampeano apresentaram valores médios de 35,00 g e 37,75 g, respectivamente. Estes valores diferem dos encontrados por Castro \& Caierão (2008), os quais observaram 39 g, para a cultivar Quartzo, e 42 g, para a Pampeano.

Bredemeier et al. (2001) mencionam que plantas originadas de sementes maiores apresentam maior taxa de emissão de folhas e maior número de afilhos por planta, entretanto, esta característica não propiciou aumento na produtividade de grãos. Andrade et al. (1997) relatam que não existem diferenças entre $\mathrm{o}$ vigor de sementes grandes ou pequenas.

O percentual de germinação foi maior quando realizado tratamento com tiametoxam, em comparação com a testemunha sem aplicação, mas não diferiu dos demais tratamentos, para a cultivar Quartzo (Tabela 1). Uma das prováveis causas para esta diferença pode ser a incidência de fungos nas sementes, já que as mesmas não foram tratadas com fungicida. 
Tabela 1. Percentagem de germinação e teste de índice de velocidade de germinação (IVG), para as cultivares de trigo Quartzo e Pampeano, em função da aplicação de inseticida e fungicida, em tratamentos de sementes (Itaqui, RS, 2011).

\begin{tabular}{lcccc}
\hline \multicolumn{1}{c}{ Tratamento } & \multicolumn{2}{c}{ Germinação (\%) } & \multicolumn{2}{c}{ IVG } \\
\cline { 2 - 5 } & Quartzo & Pampeano & Quartzo & Pampeano \\
\hline Testemunha sem aplicação & $90,0 \mathrm{~b}^{1}$ & $82,0 \mathrm{a}$ & $15,07 \mathrm{~b}$ & $13,12 \mathrm{a}$ \\
Tiametoxam & $96,0 \mathrm{a}$ & $79,0 \mathrm{a}$ & $19,95 \mathrm{a}$ & $12,37 \mathrm{a}$ \\
Carboxina + thiram & $93,0 \mathrm{ab}$ & $79,0 \mathrm{a}$ & $15,7 \mathrm{~b}$ & $12,53 \mathrm{a}$ \\
Tiametoxam + carboxina + thiram & $94,0 \mathrm{ab}$ & $80,0 \mathrm{a}$ & $15,5 \mathrm{~b}$ & $13,47 \mathrm{a}$ \\
\hline CV (\%) & 4,21 & 6,05 & 12,0 & 8,3 \\
\hline${ }^{1}$ Médias seguidas pela mesma letra, na coluna, não diferem entre si, pelo teste Tukey, a 5\%. & & &
\end{tabular}

De acordo com Sofiatti \& Schuch (2005), as sementes que não recebem tratamentos com fungicidas, contra o ataque de doenças, estão mais propensas à infecção, o que pode afetar a qualidade fisiológica das mesmas.

Cabe ressaltar que esses resultados não irão garantir um desempenho similar, posteriormente, mesmo quando a germinação é elevada, já que isto depende do potencial fisiológico e das condições do ambiente. De acordo com Krohn \& Malavasi (2004), na maioria das vezes, as sementes tratadas apresentam desempenho superior àquelas que não receberam nenhum tratamento.

Ao analisar a cultivar Pampeano, verificou-se que não houve diferença significativa entre os tratamentos testados, para o percentual de germinação (Tabela 1). Segundo Vieira et al. (1994), os testes de germinação têm despertado o interesse dos produtores de sementes, para que estes identifiquem possíveis alterações na qualidade fisiológica dos lotes. Entretanto, a germinação, pela sua própria característica de complexidade, nem sempre pode ser avaliada por apenas um teste, recomendando-se outros, para que se tenham dados mais confiáveis sobre o processo.

O índice de velocidade de germinação (IVG) foi melhor ao se usar o tiametoxam isoladamente, quando comparado aos demais tratamentos, para a cultivar Quartzo (Tabela 1). Nunes (2006) constatou que o uso de tiametoxam, no tratamento de sementes, ocasionou melhor vigor, germinação, emergência e, consequentemente, aumento na produtividade de grãos, em relação às sementes não tratadas.

Ao contrário do que ocorreu com a cultivar Quartzo, para a Pampeano, não se observou diferenças significativas entre os tratamentos, para a variável IVG. Segundo Krohn \& Malavasi (2004), o uso de tratamentos de sementes torna-se prática eficiente, para assegurar populações adequadas de plantas, principalmente quando as condições climáticas, durante a semeadura, são desfavoráveis à germinação e à rápida emergência do trigo, deixando a semente exposta por mais tempo ao ataque de pragas e doenças do solo.

De acordo com Almeida et al. (2009), o tratamento de sementes ativa várias reações fisiológicas, como a expressão de proteínas, sendo que estas interagem com vários mecanismos de defesa, permitindo que a planta suporte melhor as condições adversas do meio ambiente. Os mesmos autores constataram que, dentre os tratamentos testados, o tiametoxam estimulou o desempenho fisiológico de sementes de cenoura submetidas ou não ao estresse hídrico.

O tiametoxam acelera a germinação das sementes, por estimular a atividade de enzimas, o que

Tabela 2. Teste de frio e de envelhecimento acelerado, para as cultivares de trigo Quartzo e Pampeano, em função da aplicação de inseticida e fungicida, em tratamento de semente (Itaqui, RS, 2011).

\begin{tabular}{lcccc}
\hline \multirow{2}{*}{ Tratamento } & \multicolumn{2}{c}{ Teste de frio (\%) } & \multicolumn{2}{c}{ Envelhecimento acelerado (\%) } \\
\cline { 2 - 5 } & Quartzo & Pampeano & Quartzo & Pampeano \\
\hline Testemunha sem aplicação & $93 \mathrm{a}^{1}$ & $78 \mathrm{a}$ & $36 \mathrm{~b}$ & $13 \mathrm{c}$ \\
Tiametoxam & $93 \mathrm{a}$ & $79 \mathrm{a}$ & $28 \mathrm{~b}$ & $15 \mathrm{bc}$ \\
Carboxina + thiram & $94 \mathrm{a}$ & $79 \mathrm{a}$ & $41 \mathrm{ab}$ & $28 \mathrm{ab}$ \\
Tiametoxam + carboxina + thiram & $93 \mathrm{a}$ & $81 \mathrm{a}$ & $45 \mathrm{a}$ & $34 \mathrm{a}$ \\
\hline CV (\%) & 3,8 & 5,8 & 13,3 & 19,5 \\
\hline
\end{tabular}

${ }^{1}$ Médias seguidas pela mesma letra, na coluna, não diferem entre si, pelo teste Tukey, a 5\%. 
irá ocasionar estande e emergência de plântulas mais uniformes e melhor desenvolvimento inicial, como foi observado em sementes de soja, por Castro (2006).

$\mathrm{O}$ teste do frio, que tem como princípio diminuir a temperatura, dificultando a reorganização das membranas celulares, durante a embebição, tornando mais lentos tanto este processo como o de germinação, não demonstrou diferenças entre os tratamentos, para as variedades Quartzo e Pampeano (Tabela 2). De acordo com Krzyzanowski et al. (1991), este teste é capaz de identificar pequenas diferenças de vigor entre os lotes de sementes de trigo, devido à cultivar utilizada, tamanho das sementes, local de produção e outros fatores.

Observou-se, para o teste de envelhecimento acelerado, que o melhor tratamento foi o tiametoxam + carboxina + thiram, quando comparado com a testemunha sem aplicação, não diferindo, contudo, do tiametoxam + thiram, para as cultivares Quartzo e Pampeano (Tabela 2).

O envelhecimento de sementes ocasiona alterações metabólicas, durante o processo germinativo, incluindo o metabolismo respiratório e a funcionalidade das membranas (Nakagawa 1999), síntese de proteínas e ácidos nucleicos e metabolismo do DNA. $\mathrm{O}$ teste de envelhecimento acelerado tem como princípio que as sementes que apresentam maior vigor são mais tolerantes à umidade relativa do ar e temperaturas elevadas, com maior percentagem de germinação (Delouche \& Baskin 1973, Marcos Filho 1999). Sementes de baixa qualidade deterioram-se mais rapidamente do que as mais vigorosas, apresentando queda acentuada de sua viabilidade (AOSA 1983).

O comprimento de plântulas das cultivares testadas não apresentou diferenças em todos os tratamentos (Tabela 3). Dan et al. (1987) relatam que sementes vigorosas originam plântulas com maior taxa de crescimento, em função de apresentarem maior capacidade de transformação do suprimento de reserva dos tecidos de armazenamento e maior incorporação deste pelo eixo embrionário. Assim, os tratamentos que não diferiram entre si demonstraram que as sementes apresentaram melhor vigor.

O uso do inseticida (tiametoxam) acarretou maior acúmulo de matéria fresca, para a cultivar Quartzo, quando comparado aos demais tratamentos (Tabela 3). Observou-se melhor desempenho do tiametoxam, em relação à mistura de fungicida (carboxina + thiram), para a massa seca.

Conforme Salvadori (1999), o tratamento de sementes com inseticida ajuda na prevenção do ataque de insetos, nos estágios iniciais de desenvolvimento da cultura, além de ser uma maneira de se realizar o controle de pragas no solo, tendo-se em vista a dificuldade de se localizar, monitorar e atingir o alvo. Quando inoculados nas sementes, os inseticidas são transloucados para a plântula, após a germinação, conferindo o controle de pulgões, nos primeiros estágios de desenvolvimento da cultura, quando a praga começa a se alimentar. Neste momento, o pulgão, ao ingerir o alimento, também adquire a molécula tóxica do inseticida. Seus danos podem ser diretos, devido à sucção da seiva, e indiretos, pela transmissão do vírus do nanismo amarelo da cevada (VNAC) e pela injeção de toxinas, ocasionando a maturação antecipada da planta e, consequentemente, menor peso e qualidade de grãos (Lotici \& Gomes 2008).

A matéria fresca não apresentou diferenças entre os tratamentos, ao se utilizar a cultivar de trigo Pampeano (Tabela 3). Segundo Kryzanowski et al. (1991), o sucesso de uma lavoura é influenciado diretamente pela alta qualidade da semente a ser semeada e contribui, significativamente, para que os níveis de alta produtividade sejam alcançados, enquanto sementes de baixa qualidade comprometem a obtenção de um estande de plantas adequado, influindo, diretamente, na produtividade de grãos.

Tabela 3. Comprimento de plântulas (CP), matéria fresca (MF) e matéria seca (MS), em sementes de trigo das cultivares Quartzo e Pampeano, submetidas a tratamentos químicos (Itaqui, RS, 2011).

\begin{tabular}{|c|c|c|c|c|c|c|}
\hline \multirow{2}{*}{ Tratamento } & $\mathrm{CP}(\mathrm{cm})$ & $\mathrm{MF}(\mathrm{g})$ & MS (g) & $\mathrm{CP}(\mathrm{cm})$ & $\mathrm{MF}(\mathrm{g})$ & MS (g) \\
\hline & \multicolumn{3}{|c|}{ Cultivar Quartzo } & \multicolumn{3}{|c|}{ Cultivar Pampeano } \\
\hline Testemunha sem aplicação & $14,14 \mathrm{a}^{1}$ & $151,53 \mathrm{~b}$ & $27,34 \mathrm{ab}$ & $16,39 \mathrm{a}^{1}$ & $165,39 \mathrm{a}$ & $28,35 \mathrm{ab}$ \\
\hline Tiametoxam & $15,90 \mathrm{a}$ & $180,74 \mathrm{a}$ & $30,58 \mathrm{a}$ & $17,15 \mathrm{a}$ & $164,44 \mathrm{a}$ & $28,87 \mathrm{ab}$ \\
\hline Carboxina + thiram & $15,40 \mathrm{a}$ & $154,28 \mathrm{~b}$ & $26,52 \mathrm{~b}$ & $15,60 \mathrm{a}$ & $156,95 \mathrm{a}$ & $30,51 \mathrm{a}$ \\
\hline Tiametoxam + carboxina + thiram & $14,26 \mathrm{a}$ & $148,48 \mathrm{~b}$ & $27,62 \mathrm{ab}$ & $17,15 \mathrm{a}$ & $158,36 \mathrm{a}$ & $25,85 \mathrm{~b}$ \\
\hline $\mathrm{CV}(\%)$ & 6,9 & 6,4 & 6,2 & 6,1 & 8,0 & 5,8 \\
\hline
\end{tabular}


Em relação à matéria seca (Tabela 3), houve diferença significativa entre os tratamentos em que a mistura de fungicidas (carboxina + thiram) apresentou melhor desempenho, quando comparado ao tratamento com inseticida e fungicida (tiametoxam + carboxina + thiram).

Conforme Bittencourt et al. (2007), a mistura de fungicidas (carboxina + thiram) proporciona maior proteção à semente, contra os patógenos presentes no solo e na própria semente, principalmente quando exposta a condições desfavoráveis ao seu desenvolvimento e, também, durante o armazenamento.

Ao analisar os resultados conjuntamente, observou-se que o tratamento de semente pode ser uma ferramenta interessante para se ter plântulas mais vigorosas e, desta forma, proporcionar estandes de plantas uniformes, em função da maior percentagem de germinação e, consequentemente, melhores produtividades de trigo.

O tiametoxam $(60 \mathrm{~mL} / 100 \mathrm{~kg}$ de sementes $)$ proporcionou melhor germinação, maior velocidade de germinação e maior massa fresca e seca, para sementes da cultivar Quartzo. Carboxina + thiram (275 mL/100 kg de sementes) promoveu maior acúmulo de massa seca, para a variedade Pampeano. Tiametoxam + carboxina + thiram $(60+275 \mathrm{~mL} / 100 \mathrm{~kg}$ de sementes) permitiu melhor superação, no teste de envelhecimento acelerado, para as sementes das cultivares Quartzo e Pampeano.

\section{AGRADECIMENTOS}

Ao Conselho Nacional de Desenvolvimento Científico e Tecnológico (CNPq) e à Fundação de Amparo à Pesquisa do Estado do Rio Grande do Sul (FAPERGS), pelo auxílio financeiro à pesquisa (Processos n. 482144/2012-2/ CNPq e 12/2265-3/FAPERGS).

\section{REFERÊNCIAS}

ALMEIDA, A. S. et al. Bioativador no desempenho fisiológico de sementes de cenoura. Revista Brasileira de Sementes, Londrina, v. 31, n. 3, p. 87-95, 2009.

ANDRADE, R. V. et al. Efeito da forma e do tamanho da semente no desempenho no campo de dois genótipos de milho. Revista Brasileira de Sementes, Brasília, DF, v. 19, n. 1, p. 62-65, 1997.

ASSOCIATION OF OFFICIAL SEED ANALYSTS (AOSA). Seed vigour testing handbook. Lincoln: AOSA, 1983.
BITTENCOURT, S. R. M. et al. Eficiência do fungicida carboxim + thiram no tratamento de sementes de amendoim. Revista Brasileira de Sementes, Londrina, v. 29, n. 2, p. 214-222, 2007.

BRASIL. Ministério da Agricultura e Reforma Agrária. Regras para análise de sementes. Brasília, DF: SNDA/ DNDV/CLAV, 2009.

BREDEMEIER，C.; MUNDSTOCK，C. M.; BÜTTTENBENDER, D. Efeito do tamanho das sementes de trigo no desenvolvimento inicial das plantas e no rendimento de grãos. Pesquisa Agropecuária Brasileira, Brasília, DF, v. 36, n. 8, p. 1061-1068, 2001.

CASTRO, P. R. C. Triametoxam: uma revolução na agricultura brasileira. São Paulo: Vozes, 2006.

CASTRO, R. L.; CAIERÃO, E. Ensaio estadual de cultivares de trigo do Rio Grande do Sul, 2008. Passo Fundo: Embrapa Trigo, 2008. (Documentos, 88).

DAN, E. L. et al. Transferência de matéria seca como método de avaliação de vigor de sementes de soja. Revista Brasileira de Sementes, Brasília, DF, v. 9, n. 2, p. 45-55, 1987.

DELOUCHE, J. C.; BASKIN, C. C. Accelerated aging techniques for predicting the relative storability of seed lots. Seed Science and Technology, Zürich, v. 1, n. 2, p. 427-452, 1973.

DHINGRA, O. D. Teoria da transmissão de patógeno fúngico por sementes. In: ZAMBOLIM, L. (Ed.). Sementes: qualidade fitossanitária. Viçosa: UFV, 2005. p. 75-112.

FANAN, S. et al. Avaliação do vigor de sementes de trigo pelos testes de envelhecimento acelerado e de frio. Revista Brasileira de Sementes, Londrina, v. 28, n. 2, p. 152-158, 2006.

KROHN, G. N.; MALAVASI, M. M. Qualidade fisiológica de sementes de soja tratadas com fungicidas durante e após o armazenamento. Revista Brasileira de Sementes, Londrina, v. 26, n. 2, p. 91-97, 2004.

KRZYZANOWSKI, F. C.; FRANÇA NETO, J. B.; HENNING, A. A. Relato dos testes de vigor disponíveis para as grandes culturas. Informativo Abrates, Londrina, v. 1, n. 2, p. 15-50, 1991.

LIMA, T. C.; MEDINA, P. F.; FANAN, S. Avaliação do vigor de trigo pelo teste de envelhecimento acelerado. Revista Brasileira de Sementes, Londrina, v. 28, n. 1, p. 106-113, 2006.

LOTICI, G. R.; GOMES, L. F. S. Qualidade da farinha de trigo em função dos diferentes inseticidas e dosagens via tratamento de sementes. Cultivando o Saber, Cascavel, v. 1, n. 1, p. 143-152, 2008. 
MAGUIRE, J. D. Speed of germination-aid in selection and evaluation for seedling emergence and vigor. Crop Science, Madison, v. 2, n. 1, p. 176-177, 1962.

MARCOS FILHO, J. Teste de envelhecimento acelerado. In: KRZYZANOWSKI, F. C.; VIEIRA, R. D.; FRANÇANETO, J. B. (Eds.). Vigor de sementes: conceitos e testes. Londrina: Abrates, 1999. cap. 3, p. 1-24.

MODARRESI, R.; RUCKER, M.; TEKRONY, D. M. Accelerated ageing test for comparing wheat seed vigour. Seed Science and Technology, Zürich, v. 30, n. 3, p. 683687, 2002.

NAKAGAWA, J. Testes de vigor baseados no desempenho das plântulas. In: KRZYZANOWSKI, F. C.; VIEIRA, R. D.; FRANÇA NETO, J. B. (Eds.). Vigor de sementes: conceitos e testes. Londrina: Abrates, 1999. p. 2.1-2.24.

NUNES, J. C. Bioativador de plantas. Revista Seedsnews, Pelotas, v. 5, n. 1, p. 30-31, 2006.
OHLSON, O. et al. Teste de envelhecimento acelerado em sementes de trigo. Revista Brasileira de Sementes, Londrina, v. 32, n. 4, p. 118-124, 2010.

STEINER, J. J.; GRABE, D. F.; TULO, M. Single and multiple vigor tests for predicting seedling emergence of wheat. Crop Science, Madison, v. 29, n. 3, p. 782-786, 1989.

SALVADORI, J. R. Pragas-de-solo em culturas graniferas. Passo Fundo: Embrapa Trigo, 1999. (Comunicado técnico, 26).

SOFIATTI, V.; SCHUCH, L. O. B. Efeitos de regulador de crescimento e controle químico de doenças na qualidade fisiológica e sanitária de sementes de arroz. Revista Brasileira de Sementes, Londrina, v. 27, n. 2, p. 102-110, 2005.

VIEIRA, R. D.; CARVALHO, N. M.; SADER, R. Teste de vigor e suas possibilidades de uso. In: VIEIRA, R. D.; CARVALHO, N. M. (Eds.). Testes de vigor em sementes. Jaboticabal: Funep, 1994. p. 31. 